\title{
Grupo de Pesquisa em Tecnologia e Produção (GPTP)
}

\author{
Alexandre Prusch Züge1, Carlos Roberto Beleti Junior ${ }^{1}$, Marcelo Valério', \\ Raimundo Alberto Tostes', Robertino Mendes Santiago Junior'
}

\author{
${ }^{1}$ Campus Avançado em Jandaia do Sul - Universidade Federal do Paraná (UFPR) \\ Rua Dr. João Maximiano, 426 - 86900-000 - Jandaia do Sul - PR - Brasil \\ \{alexandrezuge, carlosbeleti,marcelovalerio,tostes,robertino\}@ufpr.br
}

O Grupo de Pesquisa em Tecnologia e Produção tem por objetivo congregar a capacidade intelectual dos docentes/pesquisadores dos cursos ofertados no recém criado Campus da Universidade Federal do Paraná (UFPR) em Jandaia do Sul (PR), centrado em áreas de pesquisa comuns para o desenvolvimento de temas regionais e nacionais. Dentre as linhas de pesquisa do grupo, a linha Educação em Ciência e Tecnologia tem por objetivo fomentar projetos de ensino, pesquisa e extensão vinculados aos cursos de Licenciatura em Ciências Exatas e Licenciatura em Computação.

Participam dos projetos e das ações desenvolvidas pelo grupo, docentes e discentes, conforme pode ser observado na Tabela 1. Foi estabelecido também, por meio de cooperação em projetos de extensão, uma parceria entre a universidade e escolas da rede estadual e municipal de Jandaia do Sul.

Tabela 1. Indicadores de recursos humanos do grupo de pesquisa

\begin{tabular}{|l|r|r|r|r|r|}
\hline $\begin{array}{c}\text { Formação } \\
\text { Acadêmica }\end{array}$ & Pesquisadores & Estudantes & Técnicos & $\begin{array}{c}\text { Colaboradores } \\
\text { estrangeiros }\end{array}$ & Total \\
\hline Doutorado & 8 & 0 & 0 & 0 & 8 \\
\hline Mestrado & 8 & 6 & 0 & 0 & 14 \\
\hline Graduação & 0 & 31 & 0 & 0 & 31 \\
\hline \multicolumn{7}{|r|}{} & \multicolumn{2}{|r|}{ Total } & $\mathbf{5 3}$ \\
\hline
\end{tabular}

Nos primeiros meses de existência do grupo, os docentes da linha de pesquisa Educação em Ciência e Tecnologia participaram dos editais disponíveis na UFPR, e conseguiram a aprovação de projetos, sendo 14 projetos entre iniciação científica e iniciação tecnológica com bolsas e 2 projetos de extensão com 6 bolsas. Pode-se destacar o projeto de extensão intitulado "Por dentro do computador: uma experiência de popularização da arquitetura de computadores", que visa a construção de um diorama para ser utilizado como ferramenta educacional no ensino de arquitetura de computadores.

Deste modo, os docentes vinculados à linha de pesquisa Educação em Ciência e Tecnologia, assim como os demais pesquisadores do grupo, pretendem contribuir para o fortalecimento da ciência no Brasil. Sobretudo, faz-se um esforço conjunto para alavancar o uso das Tecnologias de Informação e Comunicação no ambiente escolar. Por meio de incentivo aos alunos, pretende-se fortalecer e consolidar o envolvimento dos licenciandos em atividades de pesquisa nesta área. 